\title{
Censo estadounidense 2010: cifras e implicaciones de la mayor presencia de centroamericanos en Estados Unidos
}

\section{José Luis Rocha*}

Recibido: octubre de 2011 / Aceptado: noviembre de 2011

Con el tic-tac del reloj del censo estadounidense, este texto da cuenta de las cifras de migrantes centroamericanos en Estados Unidos: cuántos son, a qué ritmo crecen, dónde se ubican. Posteriormente, con base en el procesamiento de las estadísticas del Census Bureau 2010, muestra algunas características de los centroamericanos: son los más rezagados -en educación, arraigo, ingresos, obtención de ciudadanía, y de empleos estables y bien remunerados- entre los inmigrantes latinos. Sus patrones de asentamiento pueden repercutir negativamente sobre su futuro porque sus opciones geográficas son un voto político de los sin voto: contribuyen al crecimiento demográfico y de sillas en el congreso de los estados sureños, proverbial plaza de republicanos que han promovido leyes y operativos anti-inmigrantes.

Palabras clave: Inmigrantes centroamericanos / U.S. Census Bureau 2010 / políticas migratorias

\section{El reloj delator y el crecimiento de la población estadounidense}

Son las 5:20 pm del lunes 31 de octubre de 2011. El reloj poblacional de los Estados Unidos marca 312,532,360 habitantes. El 12 de agosto marcaba 311,972,624. Las pupilas se dilatan: la población creció más de medio millón en dos meses y medio. Así es: hay un reloj poblacional. Empotrado en el sitio web del Census Bureau de los

* Director del Servicio Jesuita para Migrantes - Nicaragua. Universidad Centroamericana, edificio C. Managua. Correo electrónico: jlrochag@yahoo.com 
Estados Unidos, acicatea el pánico señalando con ominoso tic-tac segundero cuántos habitantes tiene y añade un país que pondera su miedo minuto a minuto y bifurca sus desvelos entre nativos y extranjeros, blancuras y negruras, anglosajones e hispanos. El reloj -delator como el corazón del cuento de Poe- palpita infundiendo temor. Dice que cada 13 segundos hay una persona más residiendo en suelo estadounidense. Al cabo de un día, se añaden 6,646 personas. ¿Cómo? Easy easy Japanese: un bebé cada 8 segundos, un muerto cada 12 y -por último, lo más grave y evitable- un inmigrante cada 45 segundos; es decir, 1,920 inmigrantes al día y 57,600 al mes (U.S. Census Bureau, 2011a). ¿Cuántos deportados? El reloj no lo dice, pero el Department of Homeland Security deporta un inmigrante cada 80 segundos.

Si el flujo de nacimientos, defunciones e inmigrantes se mantiene igual al de la década pasada, podremos decir que en Estados Unidos cada día -entre los que nacen y los que llegan- 4,157 latinos y 633 centroamericanos se suman a su población. Estos últimos crecen a razón de 272 salvadoreños, 184 guatemaltecos, 114 hondureños, 47 nicaragüenses, 20 panameños y 16 costarricenses al día, sin contar beliceños y no clasificados. Cada hora dos nicaragüenses más habitan en suelo estadounidense.

\section{Un país multiétnico}

El censo de 2010 dice que aunque los blancos no latinos aumentaron de 194.6 a 196.8 millones, su proporción dentro del total bajó de 69 a 64\% (U.S. Census Bureau, 2011b). Y es que los 15 millones de latinos añadidos en los últimos 10 años, convierten a este grupo en el 16\% de la población total. Y si fijamos la vista en el reloj poblacional, sabremos que ya son muchos más, para horror de xenófobos y alegría de empleadores. La ola ascendente de latinos ha conseguido que, en los perfiles poblacionales de cada estado y del total del país, esté presente la distinción clave: Hispano o latino y No hispano o latino. Los latinos son el parte aguas étnico más recurrido en los estudios demográficos estadounidenses.

Los asiáticos experimentaron un crecimiento más acelerado, aunque su peso sea inferior al de los latinos. Asiáticos y latinos están haciendo realidad la constatación del periodista Jorge Ramos: "Los que creían que Estados Unidos era un país de blancos deben asomarse al Parque Central o a la Quinta Avenida para comprobar que las tonalidades de café son las predominantes. El futuro de Estados Unidos depende de que se reconozca a sí mismo como una nación multiétnica y multicultural" (Ramos, 2000, p.61). Los Estados Unidos son un país de minorías y lo serán más en un futuro más raudo que la capacidad de digestión, procesamiento y adecuación de sus políticas migratorias, sociales y laborales.

\section{El boom de los latinos y la Centroamérica exportada}

En el período intercensal 2000-2010, la población estadounidense creció apenas un 9.7\%. En los últimos 100 años, sólo la década de 1930 experimentó un menor incremento. Las décadas de los 60 y los 90 fueron testigos de un 13\% de aumento poblacional. Los años 50 recibieron un $18.5 \%$. A juzgar por la evidencia del censo, 
no estamos ante una década de explosión demográfica. Pero sí estamos en un período de arrollador crecimiento de los latinos y, entre ellos, de los centroamericanos. Los latinos son responsables de más de la mitad de los 27.3 millones en que se incrementó la población durante la última década (United States Department of Commerce, 2011). En contraste con un incremento total de la población que no llegó al 10\%, los latinos crecieron 43\%: de 35.3 a 50.5 millones. Los mexicanos contribuyeron con más de dos tercios a ese incremento, con 11.2 millones de mexicanos más. Pero su crecimiento relativo -de 54\%-fue muy inferior al 137\% -de 1.7 a casi 4 millonesde los centroamericanos. Los nicaragüenses casi duplicaron su presencia, pasando de 177,684 a 348,202. El mayor crecimiento relativo lo tuvieron los hondureños (191\%) -a pesar de ser más acosados por las redadas y filtrados por los controles migratorios-, seguidos de los guatemaltecos (180\%) y los salvadoreños (152\%).

Cuadro 1. Centroamericanos en Estados Unidos (2000-2010)

\begin{tabular}{|l|c|c|c|}
\hline \multicolumn{1}{|c|}{ Países } & 2000 & \multicolumn{1}{c|}{2010} & Diferencia \\
\hline Centroamericanos & $1,686,937$ & $3,998,280$ & $2,311,343$ \\
\hline Costarricenses & 68,588 & 126,418 & 57,830 \\
\hline Guatemaltecos & 372,487 & $1,044,209$ & 671,722 \\
\hline Hondureños & 217,569 & 633,401 & 415,832 \\
\hline Nicaragüenses & 177,684 & 348,202 & 170,518 \\
\hline Panameños & 91,723 & 165,456 & 73,733 \\
\hline Salvadoreños & 655,165 & $1,648,968$ & 993,803 \\
\hline Otros & 103,721 & 31,626 & $-72,095$ \\
\hline
\end{tabular}

Fuente: U.S. Census Bureau (2010a).

Estas cifras ponen en ridículo los resultados directos de la política de deportaciones: si a este crecimiento poblacional le añadimos la cifra de centroamericanos deportados en la última década, los centroamericanos en Estados Unidos sólo hubieran crecido un $30 \%$ más y representarían el $1.46 \%$ y no el $1.3 \%$ de la población total. Es obvio que las políticas migratorias tienen un efecto disuasorio y que, por eso, sus promotores calculan los beneficios en otros términos. Se preguntan, por ejemplo: ¿Cuánto hubiera crecido el volumen de migrantes de no existir el estrecho filtro del visado, la patrulla fronteriza, los acerados muros, los ubicuos sensores, las insomnes cámaras y los siempre listos Minute Men, Los Zetas y otros grupos criminales, siendo estos últimos los más eficientes dispositivos para disuadir a los migrantes en tránsito y en potencia?

Pero si a esas cifras agregamos un número aproximado de la indeterminable

\footnotetext{
1 En 2010 el Pew Hispanic Center calculó 11.2 millones de migrantes no autorizados en Estados Unidos, de los cuales el 87\% -9.74 millones-eran latinoamericanos. Si estimamos -un poco abusivamente-que el porcentaje de centroamericanos entre los irregulares es similar a su peso relativo en la población latina según el censo de 2010, tenemos un cálculo aproximado de 779,520 migrantes no autorizados (Passel Ë Cohn, 2011).
} 
pero indudablemente enorme cohorte de indocumentados, tenemos que los 779,520 centroamericanos indocumentados ${ }^{1}$ representan un aumento del $46 \%$ sobre los centroamericanos que había registrado el censo de 2000. Nuevamente los resultados de las deportaciones quedan en ridículo, puesto que el total de los deportados equivale solamente al 64\% de los centroamericanos que lograron burlar los panópticos controles. Esto lo podemos palpar examinando los flujos de los hondureños: a pesar de que los hondureños fueron los más castigados por las políticas migratorias en 2010 -con cuatro hondureños deportados por cada hondureño que obtuvo la residencia-, cerca de cinco hondureños lograron asentarse en Estados Unidos cada hora durante los últimos 10 años, según el reloj delator. Y podemos suponer que, dada la comprensible propensión de los migrantes no autorizados a evadir el censo, el temible reloj poblacional no da cuenta de una enorme cantidad de hondureños que se colaron en los intersticios del segundero. No es exagerado suponer que, contra vientos patrulleros y mareas de sensores, 10 hondureños se establecen cada hora en Estados Unidos.

Esas galopantes tasas han dado como resultado una "norteamericanización" de las localizaciones de los centroamericanos. Algunas importantes ciudades centroamericanas dejaron de ser los paisajes urbanos con mayor presencia de salvadoreños, guatemaltecos, hondureños... En Los Ángeles habitan más salvadoreños que en Santa Ana y más guatemaltecos que en Quetzaltenango. Es probable que Miami aloje más nicaragüenses que León. Esta relocalización da por resultado una topografía plurinacional -también podríamos llamarla ubicuidad de las nacionalidades- que tiene múltiples consecuencias. Mencionaré una repercusión política que salta a la vista: si un político salvadoreño o nicaragüense quiere recolectar fondos para su campaña, su visita será más jugosamente recompensada en una cena de beneficencia en Los Ángeles o Miami que en un mitin en San Miguel o Chinandega. La Centroamérica de la diáspora -no autorizada para votar- está teniendo una incidencia política en su desgarrada región que no tiene mucho que envidiar a la Centroamérica sedentaria, habida cuenta de que los fondos deciden más que los votos.

\section{4. ¿Cómo eran los centroamericanos que descubrieron Estados Unidos"}

En su novela Hollywood -escrita allá por 1989-, el irreverente escritor Charles Bukowski hizo una pintoresca y significativa descripción de cómo eran sus vecinos centroamericanos y cómo estaban cambiando un barrio de Los Angeles:

Aquel barrio de los alrededores de Carlton Way, cerca de Western Avenue, también estaba cambiando. Antes vivía allí gente blanca de clase baja, pero los problemas políticos en Centroamérica y otras partes del mundo habían traído una nueva clase de individuos al barrio. Los hombres eran normalmente bajos, de tez morena o muy morena, jóvenes, normalmente. Había esposas, niños, hermanos, primos, amigos. Empezaron a llenar los 
pisos y los patios. Vivían muchos en un piso y yo era uno de los pocos blancos que quedaban en el edificio.

Los niños corrían arriba y abajo, arriba y abajo por la entrada del patio. Todos parecían tener entre dos y siete años. No tenían bicis ni juguetes. Rara vez se veía a las esposas. Permanecían dentro, escondidas. Muchos de los hombres también permanecían dentro. No era conveniente que el casero se enterase de cuánta gente estaba viviendo en una sola casa. Los pocos hombres que se veían fuera eran los arrendatarios legales. Al menos ellos pagaban el alquiler. Cómo sobrevivían era un misterio. Eran pequeños, delgados, silenciosos, no sonreían. La mayoría se sentaba en los escalones del portal en camiseta, un poco inclinados hacia delante, fumando un cigarrillo de vez en cuando. Permanecían inmóviles en los escalones del porche durante horas, inmóviles. A veces compraban coches viejos, ya chatarra, y los conducían despacio por el barrio. No tenían seguro ni permiso de conducir y las matrículas estaban caducadas. Eran estoicos y tenían aguante porque, en comparación con los lugares de donde venían, ahora las cosas eran fáciles (Bukowski, 2010, pp.76-77).

La mayoría de esos centroamericanos que llegaron en los años 80 a descubrir Estados Unidos eran salvadoreños. Llegaron como asilados políticos, huyendo de la represión militar, quizás después de haber sido inquilinos de un albergue para refugiados que ni ACNUR ni la cooperación externa bilateral estaban dispuestos a seguir subvencionando. Muchos iban con varios muertos a cuestas. Como los primeros peregrinos que colonizaron la costa este de lo que sería Estados Unidos, eran perseguidos. Pusieron las primeras piedras de lo que es -latente pero latiente- el nuevo estado no libre ni asociado -sino disperso y transnacionalizado-de Centroamérica en Estados Unidos. Antes ya habían llegado nicaragüenses que se instalaron en el área de los latinos en San Francisco. Unos y otros dejaron testimonio de su historia y sus sueños en los bellos murales que adornan algunas iglesias, casas comunales, paredes, puertas de garajes y hasta tuberías. Fueron reinventando la ciudad para apropiarse del espacio, para "tropicalizar un espacio urbano frío", dijo el escritor estadounidense Mike Davis (2001, pp. 61-67). Esas primeras oleadas -unidas a la profundización de los conflictos y las desigualdades en el istmo- engendraron nuevos convidados, arrimados y, por último, mal recibidos indocumentados. El censo de 2010 nos da una caracterización fría de la sumatoria de lo que queda de esas primeras oleadas de centroamericanos y de los que se les han unido en las últimas décadas. Aunque es meramente numérico, el boceto censal muestra los contornos y líneas básicas que las ciencias sociales, la literatura y el cine -y también los chismes y otros géneros de la tradición oral- limpian, pulen y dan esplendor. 


\section{5. ¿Cómo dice el censo 2010 que son los migrantes centroamericanos?}

\subsection{Un tercio de cenroameri-gringos, mayoría de no ciudadanos y migración masculinizada}

Por su estatus como inmigrantes y nivel de ciudadanía, los centroamericanos se dividen en $35.8 \%(1,418,000)$ de nativos estadounidenses y $64.2 \%(2,542,000)$ de nacidos en el extranjero, quienes a su vez se bifurcan en un $16.7 \%$ de naturalizados y un $47.5 \%$ de no ciudadanos. Con esas proporciones, que de ninguna manera pueden reflejar la situación de la mayoría de los centroamericanos, sabemos que en la información captada por el censo predominan los centroamericanos nativos, naturalizados o residentes. La mayoría de los indocumentados están en la "caja negra" del censo. Su invisibilidad limita significativamente la posibilidad de proponer políticas adecuadas a partir del censo.

El estatus legal de cada sexo es muy distinto. En el grupo de las nacidas en el extranjero, el 30\% de las mujeres ha tramitado su ciudadanía, cosa que, en su propio grupo, sólo ha hecho el $22 \%$ de los varones. Esta marcada diferencia se debe en parte a que muchas de las mujeres que migran lo hacen en el marco de programas de reunificación familiar, jalonadas por esposos, madres o padres que están bien establecidos, evitando los riesgos y tribulaciones de la migración irregular.

Pero también se debe a que la migración masculina reciente tiene un peso relativo mayor que su equivalente femenina. Entre los hombres, el 45\% llegó a los Estados Unidos después de 1999, situación en la que se encuentra sólo el 33\% de las mujeres. En 2000-2010 el flujo de migración femenina superó a la masculina en 244 mil: 621 mil menos 377 mil. Hasta 1989 la migración centroamericana hacia Estados Unidos era predominantemente femenina: 442 mil versus 393 mil. Desde entonces, a consecuencia de las trabas y peligros del tránsito, se ha masculinizado. Este hallazgo contradice algunos clichés sobre la migración: la migración siempre ha sido masculina y sólo en los últimos años las mujeres han empezado a migrar y a acercarse a un balance de género. El censo dice todo lo contrario: las mujeres migrantes centroamericanas eran el 53\% del total hasta 1990 y ahora son el $45.5 \%$. Las políticas migratorias restrictivas han tenido un sesgo de género en el caso de los centroamericanos. No lo tienen para los mexicanos: su flujo siempre ha sido y sigue siendo mayoritariamente masculino. Tampoco para los cubanos, de persistente predominio femenino, salvo durante el período especial.

Para los centroamericanos, este desbalance se traduce en un creciente peso de los hogares cuya jefatura descansa en hombres que migraron solos y que cohabitan con personas a las que no están atadas por vínculos familiares. Por eso han proliferado los hogares no familiares de más de tres personas que se unen para pagar los costosos alquileres de los apartamentos. El 15\% de los hogares de inmigrantes centroamericanos formados por no familiares tienen tres o más personas, situación en la que se encuentra apenas el 4\% de los cubanos, el 5\% de los sudamericanos y el 9\% de los mexicanos. De manera indirecta, las políticas migratorias están bloqueando la unidad de las familias de inmigrantes centroamericanos. Las contradicciones entre 
valores sociales y políticas estatales estadounidenses son palpables. Sus conmovedores efectos son denunciados en cientos de testimonios.

\section{2. ¿Recién llegados = Empleos no profesionales y bajos salarios?}

Esta situación está ligada a -causada y/o reforzada por- las ocupaciones y los salarios. A menor salario, menores posibilidades de independencia y unidad familiar. Los trabajadores centroamericanos se ubican, mucho más que el promedio de los latinos, en los sectores de la construcción y mantenimiento (20 versus 14\%) y la producción (12 versus 8.6\%). El 31\% que trabajan en servicios lo hacen fundamentalmente en la limpieza. En cambio, tienen menos presencia en los trabajos profesionales: 10.6 versus $19 \%$ del promedio de los latinos, el 31\% de los cubanos y el 27\% de sudamericanos y puertorriqueños. Casi la cuarta parte de los varones que trabajan (23\%) y más de un tercio de las mujeres (34\%) tienen empleos a tiempo parcial. En situación semejante sólo se encuentra el 16 y el 25\% de sudamericanos y sudamericanas.

La ubicación laboral constriñe las posibilidades salariales. Cerca de un tercio de los centroamericanos no llegan a ganar siquiera 1,700 dólares al mes, condición que sólo afecta al 15\% de cubanos y sudamericanos y al 26\% de los mexicanos. Apenas el 14\% de los centroamericanos gozan de un salario de más de 4 mil dólares al mes, adquisición más frecuente entre mexicanos (18\%) y bastante más común entre cubanos (34\%) y sudamericanos y puertorriqueños $(30 \%)$.

Aparentemente existe una correlación entre esos salarios y el arraigo generacional: $64 \%$ de los centroamericanos son inmigrantes, $30 \%$ son hijos de inmigrantes y apenas el $5.6 \%$ son nietos de inmigrantes. Los mexicanos tienen un $30.6 \%$ de nietos de inmigrantes y los puertorriqueños un $92.6 \%$. Son grupos cuyo establecimiento data de varias generaciones. Pero el 7.4\% de los sudamericanos se aproxima mucho a la cifra centroamericana. El establecimiento por generaciones no es el factor de mayor peso para determinar empleos y salarios.

Un asunto es que los inmigrantes nacidos en Sudamérica han conseguido la ciudadanía en mayor proporción que los centroamericanos: 28 versus $16.7 \%$. Pero hay otro factor que pesa más y que incluso puede ser determinante del acceso a la ciudadanía estadounidense, ya que obviamente no lo es la antigüedad: tanto en los inmigrantes centroamericanos como en los sudamericanos el 39\% llegaron en la última década. Ese factor es la educación.

\subsection{Tienen escasa escolaridad}

Los centroamericanos siguen siendo los inmigrantes con menos educación formal de todos los migrantes hispanos, un grupo poblacional ya de por sí estigmatizado por su baja educación. De los centroamericanos de 25 años o más, el 32\% no llegó a noveno grado, nivel que no alcanzaron el 21 y el $25 \%$ de latinos y mexicanos y apenas el $8.5 \%$ de los sudamericanos. El 48\% de los centroamericanos no llegaron a la secundaria, situación en la que se encuentra el $37 \%$ que promediaron los latinos y el 43\% de los mexicanos, y un exiguo 16\% de los sudamericanos. Sólo el $2 \%$ de los centroamericanos tienen estudios de postgrado, en contraste con el 
$10 \%$ de los sudamericanos. La educación es un factor determinante del ingreso, en mucha mayor medida en que lo es -para un grupo nacional- la obtención de la ciudadanía o el peso de los migrantes de tercera generación, tan importante entre los mexicanos. La educación es determinante en la comparación entre centroamericanos y sudamericanos, donde el resto de variables acusan valores similares. Pero no lo es en la comparación con cubanos y puertorriqueños. Los ciudadanos de esas nacionalidades obtienen mejores salarios que los sudamericanos, pese a sus menores niveles educativos.

\section{4. "Juventud, divino tesoro, te vas para no volver"}

La inmigración centroamericana a Estados Unidos tiene una gran virtud: su carácter juvenil. El 29\% de los migrantes centroamericanos son jóvenes de entre 20 y 34 años. Los migrantes de otras regiones se aproximan, pero no llegan a esa cifra: 25\% de los mexicanos, $22 \%$ de los sudamericanos y $19 \%$ de los cubanos. Centroamérica aporta fuerza joven. La mitad de los centroamericanos que viven en Estados Unidos tienen entre 25 y 54 años. Están en plena producción. Constituyen un pequeño bono demográfico que Centroamérica obsequia a los Estados Unidos. El rango de 35 a 44 años concentra al 18\%. Son los centroamericanos que llegaron hace una década o dos, inmigrantes que han alcanzado mayor estabilidad. Los centroamericanos de más de 54 años son apenas el $9 \%$. Hay un importante 25\% menor de 15 años. Son el bono demográfico del futuro inmediato.

Centroamérica hace a Estados Unidos una pequeña contribución que ayuda a mantener un mercado laboral joven, trabajando a pleno pulmón. Ese bono también inyecta fondos a la seguridad social, garantizando un flujo neto positivo: más aportes en cotizaciones que gastos. Las políticas públicas deberían atender a estos hechos. A menudo se apela a la opinión pública esgrimiendo estos datos. Pero las percepciones masivas no suelen atender a razones. Las políticas -al menos por puro cálculo egoísta-sí deberían basarse en un análisis racional del rol que juegan los migrantes en esa economía y crear condiciones para que ese aporte sea potenciado, agradecido y multiplicado.

\subsection{Estatus marital}

En la migración femenina, más que en la masculina, es notoria la mayor presencia de personas con unión estable - 46 vs. $44 \%$ - y también la de quienes tienen a su cónyuge viviendo con ellas -43 vs. $37 \%$. ¿Estas cifras reflejan que una porción importante de inmigrantes mujeres priorizan la unidad familiar, sea porque suelen migrar acompañadas o porque están en Estados Unidos como consecuencia de un proyecto de reunificación familiar? ¿O reflejan una mayor tendencia masculina a romper los lazos de pareja por efecto de la distancia y el imperativo de adaptación a un medio de muchos requerimientos?

Por otro lado, también hay proporcionalmente más mujeres separadas o divorciadas que hombres: 13.2 vs. $7.6 \%$. Y en cambio hay más "Nunca casados" entre los hombres (48\%) que entre las mujeres (37\%). ¿Quizás los hombres tienden 
más a no confesar de un lado de la frontera lo que Dios unió del otro lado? ¿O quizás hay muchas mujeres que migran tras romper sus ataduras matrimoniales?

Las especificidades de la migración sólo pueden emerger en un análisis que compare la situación de los migrantes con la de los no migrantes. Urge evitar la falacia de la media tabla, tara muy extendida en los estudios migratorios, que a menudo hacen pasar por una rareza migratoria lo que es una situación común a una población similar, sea inmigrante o no. Para explorar una comparación accesible -muy lejos de la que necesitamos para penetrar en esta realidad-, tomé como punto de referencia el Censo nacional de población de Nicaragua, realizado en 2005, por ser la fuente estadística regional más próxima en el tiempo al censo estadounidense. A fin de posibilitar un uso pertinente de esa información, empecé por excluir a la población menor de 15 años, de la que el censo estadounidense hace caso omiso para el cálculo del estatus marital. En segundo lugar, ponderé -distinguiendo por sexo- los resultados del Censo 2005 de Nicaragua, según el peso de los rangos etarios en la población migrante, para eliminar las diferencias debidas a las distintas proporciones de edad entre el universo poblacional de Nicaragua y el conjunto de centroamericanos que residen en Estados Unidos. Podemos presumir que en un universo de migrantes centroamericanos donde la mitad tienen entre 25 y 54 años, entre ellos tenderá a haber menos solteros y más personas haciendo vida de pareja o con uniones disueltas.

El resultado de la ponderación es una tabla que contrasta información sobre el estatus marital de nicaragüenses y centroamericanos. Las primeras dos columnas, útiles únicamente para efectos comparativos, muestran cómo serían las cifras si la población nicaragüense tuviera una pirámide poblacional semejante a la de los centroamericanos que están en Estados Unidos. La tercera y cuarta columnas reflejan la situación de éstos de acuerdo al censo estadounidense de 2010.

Cuadro 2. Cuadro comparativo de la situación marital de nicaragüenses que residen en Nicaragua y centroamericanos que residen en Estados Unidos

\begin{tabular}{|l|c|c|c|c|}
\cline { 2 - 5 } \multicolumn{1}{c|}{} & \multicolumn{2}{c|}{ Censo 2005 Nicaragua } & \multicolumn{2}{c|}{ Censo 2010 EEUU } \\
\cline { 2 - 5 } \multicolumn{1}{c|}{} & Hombres & Mujeres & Hombres & Mujeres \\
\hline Con Pareja & 65.4 & 59 & 44.1 & 46 \\
\hline Unión disuelta & 4 & 12.6 & 7.6 & 13.2 \\
\hline Soltero (a) & 29.3 & 22.4 & 47.8 & 37 \\
\hline Viudo (a) & 1.3 & 6 & 0.5 & 3.8 \\
\hline
\end{tabular}

Fuente: Elaboración propia con base en el Censo nacional 2005 de Nicaragua (INIDE, 2005) y el U.S. Census Bureau (2010b).

Apoyándome en estas cifras puedo sostener que la viudez y la soltería son relativamente más abundantes entre quienes migran que entre quienes no lo hacen. Mujeres y hombres pueden tomar más fácilmente la decisión de migrar si no tienen pareja. Y aunque en general hay más hombres solteros que mujeres, la brecha de género -diferencia entre hombres y mujeres- es similar entre migrantes y no migrantes. La migración no parece alterar los desbalances de género en la soltería. Pero sí parece 
haber una correlación entre migración y diferencias de género que se plasma en otras tres condiciones maritales: la viudez, las uniones disueltas y el emparejamiento. Las mujeres van a la cabeza en el primer caso; los hombres en el segundo. Las notables diferencias saltan a la vista, pero las proporciones son muy diversas entre migrantes y no migrantes. Los hombres con uniones disueltas son proporcionalmente casi el doble entre los migrantes. No sabemos si las congojas de amores desairados son detonantes de muchos itinerarios migratorios. Pero sabemos que existe un alto porcentaje de hombres que rompen relaciones con la media naranja tropical que dejaron en Centroamérica e inician una relación con una media manzana o media naranja adaptada a climas más templados.

En cambio, hay 7.6 viudas por cada viudo entre las migrantes, en contraste con una proporción de 4.6 a 1 entre no migrantes. Suelen ser mujeres que enviudaron jóvenes. Algunas son viudas de guerra, que pidieron asilo político en los 80. Otras -de menor cuantía pero número creciente- son viudas refugiadas que huyen del crimen organizado, las maras y el fuego cruzado del narcotráfico.

Más llamativa es la inversión de proporciones en las y los emparejados. Entre quienes no migran, los hombres emparejados predominan: 65.4 sobre el 59\% de las mujeres. Entre inmigrantes, las mujeres en unión formal o informal se colocan dos puntos arriba de los hombres, invirtiendo las proporciones en un total de más de ocho puntos porcentuales. No se trata, por tanto, de que las mujeres migrantes tiendan más a estar emparejadas que las no migrantes -de hecho, lo están mucho menos, 13 puntos porcentuales por debajo-, sino de que el desequilibrio en la composición de género de la migración centroamericana -mayoría masculina-y su propensión a la endogamia convergen para incrementar el número y peso relativo de varones solteros.

\subsection{Rostro migrante y rostro político}

A primera vista el censo aparece como un instrumento aséptico, pero tiene un efecto político directo e inmediato. Sus datos son utilizados para distribuir el número de representantes de cada estado de la unión en el congreso estadounidense. Por eso los patrones de asentamiento de los inmigrantes tienen implicaciones políticas: ayudan a definir qué estados ganarán y qué estados perderán sillas.

Los 10 estados que perdieron sillas como consecuencia del censo de 2010 son predominantemente demócratas, situados en el noreste y el medio-oeste, áreas de residencia de población más progresista. En cambio, cinco de los ocho que ganaron sillas son mayoritariamente republicanos (Newport, 2010). New York y Massachusetts, dos estados donde los demócratas son muy fuertes, perdieron sillas. Los estados de Texas, Arizona, Carolina del Sur, Utah y Georgia han exhibido un inveterado conservadurismo. Los tres primeros han aprobado legislaciones antiinmigrantes, y Utah es el estado más conservador del país.

Políticos "demócratas" no equivalen a una garantía de políticas migratorias menos represivas y más humanas. Pero es indudable que los republicanos cuentan en sus filas a los políticos que más se han destacado por sus actitudes, declaraciones y propuestas xenófobas: el gobernador de California Arnold Schwarzenegger, la gobernadora de Arizona Jan Brewer que aprobó la tan polémica como paranoica 
ley, el senador James Sensenbrenner que lanzó una propuesta de política migratoria de marcado talante represivo, el senador Russell Pearce que impuso la verificación electrónica del estatus legal de los empleados y el hollywoodense sheriff Joe Arpaio.

Esto quiere decir que un mayor poder en manos republicanas no es buena noticia para los inmigrantes. Y desafortunada e históricamente los cambios demográficos han inducido cambios de poder que conceden ventaja a los republicanos en detrimento de los demócratas. El tradicionalmente demócrata estado de New York pasó de 45 a 27 sillas en 1940-2010, mientras Texas -plaza de los republicanossaltó de 21 a 36 sillas. Texas mantuvo su tendencia a acaparar más sillas debido a su extraordinario crecimiento poblacional en los últimos 10 años: de 21 a 25 millones.

La redistribución de sillas tras el conteo del censo está plasmada en la siguiente imagen.



Ilustración 1. Mapa de la redistribución de sillas en el congreso estadounidense (2010)

Fuente: U.S. Census Bureau (2010a)

La propensión de los migrantes a asentarse más en el sur ha acentuado esa tendencia. La mitad de la población latina reside en tres estados: California, Texas y Florida. En California reside el 28\% de los latinos que hay en estados Unidos. Texas y Florida tienen el 19 y el $8 \%$. Los centroamericanos no se alejan de este patrón: $50 \%$ habita en el oeste y $35 \%$ en el sur; $28 \%$ en California, $11 \%$ en Texas y $11 \%$ en Florida. Pero también tienen un importante $9 \%$ en New York. De hecho, la ciudad de New York es la localidad de más de 100 mil habitantes con mayor porcentaje de latinos. Hialeah en Florida, cabeza de playa de nicaragüenses, ocupa el tercer lugar entre las localidades donde los latinos son la mayoría -con su 94.7\%-, sólo superada por el este de Los Ángeles en California y Laredo en Texas, con sus 97.1 y 95.6\% respectivamente (U.S. Census Bureau, 2011c).

La población de estados sureños como Nevada, Arizona, Utah y Texas aumentó en 35, 25, 24 y 21\%. Su incremento duplicó y hasta triplicó el incremento nacional. A ese atlético salto demográfico los latinos contribuyeron con su aumento del $82,46,78$ y $42 \%$. Y los centroamericanos, desde su posición de ser un minúsculo $8 \%$ de los latinos, contribuyeron con su aumento del 200, 180, 208 y $187 \%$. 
En las siguientes tablas es posible apreciar la creciente presencia y predilección de los inmigrantes centroamericanos por dos de los estados sureños ganadores.

Cuadro 3. Centroamericanos en Texas

\begin{tabular}{|l|r|r|r|}
\cline { 2 - 4 } \multicolumn{1}{c|}{} & 2000 & 2010 & Diferencia \\
\hline Centroamericanos & 146,723 & 420,683 & 273,960 \\
\hline Costarricenses & 3,302 & 6,982 & 3,680 \\
\hline Guatemaltecos & 18,539 & 66,244 & 47,705 \\
\hline Hondureños & 24,179 & 88,389 & 64,210 \\
\hline Nicaragüenses & 7,487 & 19,817 & 12,330 \\
\hline Panameños & 7,076 & 13,994 & 6,918 \\
\hline Salvadoreños & 79,204 & 222,599 & 143,395 \\
\hline Otros & 6,936 & 2,658 & $-4,278$ \\
\hline
\end{tabular}

Fuente: U.S. Census Bureau (2011c)

Cuadro 4. Centroamericanos en Florida

\begin{tabular}{|l|c|c|c|}
\cline { 2 - 4 } \multicolumn{1}{c|}{} & 2000 & 2010 & Diferencia \\
\hline Centroamericanos & 202,772 & 432,665 & 229,893 \\
\hline Costarricenses & 11,248 & 20,761 & 9,513 \\
\hline Guatemaltecos & 28,650 & 83,882 & 55,232 \\
\hline Hondureños & 41,229 & 107,302 & 66,073 \\
\hline Nicaragüenses & 79,559 & 135,143 & 55,584 \\
\hline Panameños & 15,117 & 28,741 & 13,624 \\
\hline Salvadoreños & 20,701 & 55,144 & 34,443 \\
\hline Otros & 6,268 & 1,692 & $-4,576$ \\
\hline
\end{tabular}

Fuente: U.S. Census Bureau (2011c)

Las redes que facilitan la inserción socio-económica de los inmigrantes tienen un efecto boomerang, dificultando la inserción política. Los inmigrantes han aportado un bono político demográfico: los migrantes han contribuido al crecimiento poblacional que ha dado mayor peso demográfico y, en consecuencia, sillas en la cámara de representantes a los estados del sur, tradicionalmente más conservadores que los del norte y el este.

De momento, el peso demográfico latino no se traduce en un peso político que puedan aprovechar. Los latinos son responsables del 51\% del crecimiento poblacional. Pero como los latinos son muy jóvenes para votar o carecen de ciudadanía, su peso demográfico no se traduce de manera inmediata en un peso electoral. De los 48.4 millones de latinos que había en 2009, sólo 20.1 millones podían votar. El resto no podían votar por ser muy jóvenes -15.5 millones- o no tener 
ciudadanía -12.8 millones. Casi el 30\% de los centroamericanos no puede votar por su minoría de edad.

Sin embargo, el tiempo es un gran escultor de paisajes y política. Los latinos y, entre ellos, los centroamericanos continúan engrosando las filas de los votantes. En la última década, seis millones de latinos se sumaron a los electores. En los siguientes años presenciaremos el despliegue de esa misma tendencia: medio millón de latinos al privilegiado bolsón de los votantes. Los votantes latinos están tres veces más presentes en los estados conservadores que ganaron sillas. Son el $15.2 \%$ de los votantes, comparado con el $5.4 \%$ que representan en los estados que perdieron votos (López \& Taylor, 2011). ¿Cambiarán ellos las tendencias conservadoras? En cualquier caso, los políticos deberán tomar en cuenta sus intereses. ¿Serán intereses abiertos a la migración o experimentarán los latinos una asimilación perversa? Los migrantes bien establecidos -con ciudadanía que les permite votar- podrían interesarse en detener la inmigración. Ya lo hacen -y no sólo con asépticos votos- los muchos latinos que trabajan en la patrulla fronteriza y los controles de migración y aduanas.

Según las categorías censales, los latinos pueden pertenecer a cualquier raza. En la boleta censal pueden autoidentificarse como blancos, negros o afroamericanos, asiáticos, amerindios, etc. Raza y origen nacional son variables distintas, que a veces pueden coincidir: los latinos también pueden identificarse como de raza latina, salvadoreña, nicaragüense, etc., en cuyo caso sus respuestas serán (con) fundidas en un variopinto bolsón etiquetado "Alguna otra raza". Sólo el 40\% de los centroamericanos quisieron identificarse a partir de su origen nacional. El resto optó por incluirse dentro de una raza bien establecida: $52 \%$ blancos, 5.2 multirracial, 1.5 amerindios y $1.2 \%$ afroamericanos fueron las categorías más recurridas. ¿Ese aplastante $52 \%$ que se bautizó como blanco estará realmente convencido de su blancura o usa la etiqueta como una estrategia de adaptación? ¿Votarán a favor de su blancura o a favor de los nuevos migrantes?

\section{Reflexiones finales}

Según el periodista Jorge Ramos:

En 1970 ocho de cada 10 californianos eran blancos. Hoy son otra minoría más. Y conforme disminuye el número de blancos aumenta el de hispanos. De acuerdo con la Oficina del Censo de Estados Unidos y el Departamento de Finanzas, a principios del 2000 en California no había ninguna raza o grupo étnico que fuera mayoritario. Los blancos no alcanzaban el 50\% de la población, los hispanos constituían el 31\%, los asiáticos el 12 y los negros o afroamericanos un 7\%. El cambio era dramático (Ramos, 2000, pp. 213-214).

El cambio continúa: en 2010 los latinos subieron al 37\%, los asiáticos al $13 \%$, los afroamericanos bajaron al $6 \%$ y destaca un nuevo grupo, los mixtos, interraciales, 5\% que pertenecen a dos o más razas (U.S. Census Bureau, 2010c). Los blancos aparentemente se incrementaron hasta llegar al 57.6\%. Pero la razón 
de ese incremento se basa en su inclusión de algunos latinos y otros grupos étnicos. Con persistente - ¿y deliberada?- ambigüedad, las categorías del censo estadounidense admiten o prohíben combinaciones.

El censo diseña categorías que a veces son mutuamente excluyentes y categorías que pueden subsumir a otras, una segmentación cuya lógica es difícil de discernir. Por ejemplo, la blancura es una denominación de origen y un sello racial. Blanco es un concepto ambiguo. Puede significar "nativo" o "de rasgos caucásicos". Por ese hilo se llega a un ovillo de confusiones. ¿Por qué un latino puede ser blanco, pero un garífuna no puede ser un afroamericano? ¿Cómo se asigna la "americanidad", con ese persistente guión? ¿Por qué alguien cuyos ancestros vinieron de África es siempre un afroamericano, pero jamás se habla de asiatico-americanos o hispanoamericanos (¡o de anglo-americanos y euro-americanos!)? ¿Por qué se habla de asiáticos o latinos a secas? ¿Cuándo ser latino o asiático puede ser un origen regional y cuándo un encasillamiento étnico? ¿Por qué la etiqueta "latino" no está reñida con la blancura y por qué la africanidad nunca puede ser blanqueada? Desde sus inicios en el siglo XVIII, el censo estadounidense ha reconfigurado sus categorías para adecuarlas a las manías de turno entre académicos y políticos. Las categorías reflejan lo políticamente correcto de una década o incluso períodos más extensos. Buscan también establecer distinciones que alimenten el diseño de políticas públicas que asignan cuotas de acceso a empleos estatales y estuarios universitarios por grupos étnicos.

Por eso son tan importantes las distinciones que hacen y las que no hacen. Por eso importan tanto sus distinciones como sus confusiones. Ambas son factores dialécticos que reflejan y moldean cómo una sociedad se concibe a sí misma. Su onda expansiva impacta las políticas públicas, la percepción sobre los grupos sociales y las modas xenófobas, que van eligiendo sucesivos chivos expiatorios.

Los centroamericanos, a pesar de su autoreclamo de blancura, son los más rezagados -en educación, arraigo, ingresos, obtención de ciudadanía y de empleos estables y bien remunerados- entre los inmigrantes latinos, que a su vez van a la zaga de los europeos y asiáticos. Su precariedad es un reto para sus gobiernos: el de un lado y los del otro lado del río Grande... o Bravo, según se vaya o se venga. Desafortunadamente, con ese voto no oficial y masivo que es el peso demográfico, parecen haber contribuido a políticas que no los van a favorecer, porque los republicanos no sólo son el partido más alérgico a los inmigrantes, sino también el menos amigo de las políticas sociales.

El reloj censal sigue latiendo. Muchos centroamericanos -quizás varios miles- han llegado a -o nacido en- Estados Unidos mientras avanzo en este texto. No tengo duda de que son más y que enfrentan peores condiciones que las registradas por el censo. No olvidemos que el tiempo es tan poroso como las fronteras y que en los intersticios del segundero se cuelan los indocumentados.

\section{Referencias bibliográficas}

Bukowski, C. (2010). Hollywood. Barcelona: Editorial Anagrama.

Davis, M. (2001). Magical urbanism: Latinos Reinvent the U.S. City. San Francisco: Verso. 
Instituto Nacional de Información para el Desarrollo [INIDE]. (2005). VIII Censo de Población y IV de Vivienda. Managua: Autor.

Newport, F. (2010, diciembre). All 10 States Losing Congressional Seats Tilt Democratic. Gallup. Recuperado el 1 de noviembre de 2011, de http://www. gallup.com/poll/145397/states-losing-congressional-seats-tilt-democratic. aspx

Passel, J. S. \& Cohn, D. (2011, febrero). Unauthorized Immigrant Population: National and State Trends, 2010. Washington, D.C.: Pew Hispanic Center. Recuperado el 23 de octubre de 2011, de http://pewhispanic.org/reports/report. php? ReportID=133

Ramos, J. (2000). La otra cara de América. Historias de los inmigrantes latinoamericanos que están cambiando Estados Unidos. México: Editorial Grijalbo.

U.S. Census Bureau. (2010a). American FactFinder. Recuperado el 16 de septiembre de 2011, de http://factfinder.census.gov/ servlet/SAFFPeople?_event=Search\&geo_id=04000US28\&_ geoContext=01000US | 04000US28\&_street $=\&_{-}$county $=\&$

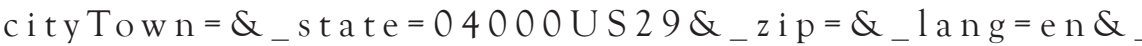
sse $=$ on $\&$ ActiveGeoDiv $=$ geoSelect $\& \_$useEV $=\&$ pctxt $=f$ ph $\&$ pgsl $=040 \&$ _ submenuId=people_ $10 \& d_{\text {s }}$ name $=$ null $\&_{-}$ci_nbr=null\&qr name $=$ null\& $\&$ reg=null\%3Anull\&_keyword $=\&$ \&_industry $=$

U.S. Census Bureau. (2010b). Annual Social and Economic (ASEC) Supplement, 2010. Current Population Survey. Recuperado el 15 de septiembre de 2011, de http://www.census.gov/cps/

U.S. Census Bureau (2010c). 2010 Census Interactive Population Search. Recuperado el 8 de noviembre de 2011, de http://2010.census.gov/2010census/popmap/ ipmtext.php?fl=06

U.S. Census Bureau. (2011a). U.S. and World Population Clocks. Recuperado el 31 de octubre de 2011, de http://www.census.gov/main/www/popclock.html

U.S. Census Bureau. (2011b, marzo). 2010 Census Shows America's Diversity. Recuperado el 30 de octubre de 2011, de http://2010.census.gov/news/ releases/operations/cb11-cn125.html

U.S. Census Bureau. (2011c, mayo). The Hispanic Population: 2010. 2010 Census Briefs. Recuperado el 16 de septiembre de 2011, de www.census.gov/prod/ cen2010/doc/sf1.pdf

United States Department of Commerce. (2011, 24 de marzo). U.S. Census Bureau Releases New Race and Population Data Based on Findings from 2010 Census. Recuperado el 22 de octubre de 2011, de http://www.commerce.gov/ blog/2011/03/24/us-census-bureau-releases-new-race-and-population-databased-findings-2010-census

López, M. H. \& Taylor, P. (2011, enero). The 2010 Congressional Reapportionment and Latinos. Washington, D.C.: Pew Hispanic Center. Recuperado el 1 de noviembre de 2011, de http://pewhispanic.org/reports/report. php?ReportID=132 